\title{
Media Fun Thinkers Berbasis Soal Calistung pada Tema 7 Benda, Hewan dan Tanaman di Sekitarku untuk Siswa SD Kelas 1
}

\author{
Jummita1*, I Gusti Ayu Tri Agustiana2 , I Ketut Dibia ${ }^{3}$
}

1,2,3 Prodi Pendidikan Guru Sekolah Dasar, Universitas Islam Riau, Pekanbaru, Indonesia

\section{ART I CLE I N F O \\ Article history: \\ Received June 22, 2021 \\ Revised June 30, 2021 \\ Accepted July 15, 2021 \\ Available online July 25, 2021 \\ Kata Kunci: \\ Media Fun Thinkers, Calistung \\ Keywords: \\ Media Fun Thinkers, Calistung

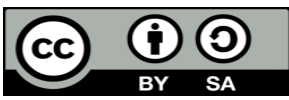

This is an open access article under the CC BY-SA license.

Copyright (C) 2021 by Author.

Published by Universitas Pendidikan Ganesha.

\begin{abstract}
A B S T R A K
Penggunaan gadget secara terus menerus dapat memberikan dampak buruk bagi siswa. Hal tersebut berdampak pada pola perilaku dan aktivitas belajar siswa. Diperlukannya media penyeimbang dalam pembelajaran daring yaitu media yang bersifat konkret. Penelitian ini bertujuan untuk menciptakan media fun thinkers berbasis soal calistung yang dapat meningkatkan minat belajar siswa dan menyeimbangkan pembelajaran daring. Jenis penelitian ini yaitu penelitian pengembanga dengan menggunakan prosedur ADDIE. Subjek uji coba pada penelitian ini yaitu 2 orang ahli materi soal, 2 orang ahli media pembelajaran, 2 orang praktisi dan 7 orang siswa. Metode yang digunakan untuk mengumpulkan data pada penelitian ini adalah metode kuesioner. Instrumen pengumpulan data yang digunakan pada penelitian ini adalah rating scale. Teknik analisis data yang digunakan pada penelitian ini yaitu analisis data deskriptif kualitatif dan kuantitatif. Hasil penelitian yaitu hasil penilaian yang diberikan oleh ahli materi pelajaran memberikan penilaian 4,63 (sangat baik), ahli media pelajaran memberikan penilaian 4,82 (sangat baik), penilaian yang diberikan oleh ahli respon praktisi yaitu 4,85 (sangat baik) dan hasil uji respon siswa media yaitu 4,95 (sangat baik), hasil tersebut menunjukakan media fun thinkers berbasis soal calistung layak digunakan. Media fun thinkers berbasis soal calistung dapat digunakan dalam proses pembelajaran. Implikasi penilaian yaitu media pembelajaran ini dapat digunakan oleh guru dan dalam proses pembelajaran.
\end{abstract}

\section{A B S TRACT}

Continuous use of gadgets can have a negative impact on students. This has an impact on behavior patterns and student learning activities. The need for balancing media in online learning is media that is concrete. This type of research is development research using the ADDIE procedure. The test subjects in this study were 2 subject matter experts, 2 learning media experts, 2 practitioners and 7 students. The method used to collect data in this study is the questionnaire method. The data collection instrument used in this study was a rating scale. The data analysis technique used in this research is descriptive qualitative and quantitative data analysis. The results of the study are the results of the assessment given by subject matter experts giving an assessment of 4.63 (very good), learning media experts giving an assessment of 4.82 (very good), the assessment given by practitioner response experts is 4.85 (very good) and the results of the media student response test were 4.95 (very good). So media fun thinkers based on calistung questions can be used in the learning process. The implication of the assessment is that this learning media can be used by teachers and in the learning process.

\section{PENDAHULUAN}

Indonesia saat ini sedang dikejutkan dengan mewabahnya penyakit yang disebabkan oleh virus corona yang dapat menyebabkan kematian (Dewi, 2020; Wahyono, Husamah, \& Budi, 2020). Hal ini yang menyebabkan pemerintah melakukan antisipasi penyebaran covid-19 dengna mengeluarkan kebijakan pembatasan sosial, bekerja dan belajar dari rumah (Ayuni et al., 2021; Shaik Alavudeen et al., 2021). Pademi ini berdampak pada seluruh aspek kehidupan terutama bidang pendidikan. Saat ini pembelajaran harus dilaksanakan secara daring (Abidah, et al, 2020; Atmojo \& Nugroho, 2020). Pada pembelajaran daring ini juga tentu memperhatikan ketentuan seperti aktivitas belajar harus menciptakan pembelajaran bermakna, tidak membebani siswa, memperhatikan kondisi, mempertimbangkan fasilitas belajar di rumah, serta dapat memberikan umpan balik pada siswa (Atmojo \& Nugroho, 2020; Baber, 2021). Kondisi pembelajaran daring sesungguhnya menuntut siswa untuk dapat belajar mandiri. Pembelajaran daring sangat berbeda dengan pembelajaran tatap muka di sekolah. Pembelajaran daring lebih menekankan kesiapan dan ketelitan siswa dalam mengolah dan menerima pembelajaran yang disajikan secara online oleh guru (Aji, 2020; Wardani et al., 2020). Hal ini yang menyebabkan siswa harus memiliki kesiapan 
dalam proses pembelajaran daring, khusunya bagi anak sekolah dasar diperlukan pengawasan dan dukungan orang tua yang akan memudahkan siswa dalam menerima informasi saat pembelajaran daring (Ariebowo, 2021; Dewi, 2020; Wulandari \& Purwanta, 2021).

Permasalahan yang terjadi saat ini yaitu beberapa anak menggunakan fasilitas yang diberikan orangtua seperti handphone tidak untuk belajar, sehingga akan berdampak buruk pada pola perilaku anak (Hendriawan \& Septian, 2019; Pebriana, 2017). Anak akan bergantung dan menjadi suatu kebutuhan menggunakan gadget sebagai kegiatan rutin yang harus dilakukan dalam kehidupan setiap harinya (Ompi et al., 2020). Hampir setiap anak sudah dapat menggunakan gadget terutama ketika pembelajaran daring yang dilakukan secara online, sebaiknya penggunaan gadget harus didampingi dan diawasi oleh orang tua agar dampak buruk akibat penggunaan gadget dapat diminimalisir (Lilawati, 2020; Yulianingsih et al, 2020). Salah satu hal yang tidak dapat dipungkiri akibat dari penggunaan gadget pada anak menyebabkan anak lebih senang bermain dengan gadget, kurangnya interaksi baik dengan teman dan orang tua, kemampuan psikomotorik berkurang, kesulitan bersosialisasi, kurangnya minat belajar dari anak dan adanya kesulitan beradaptasi dengan materi pelajaran (Kharisma Bismi Alrasheed \& Aprianti, 2011; Widiyono, 2020). Guru harus berinovasi menciptakan pembelajaran yang menyenangkan bagi siswa sehingga siswa tidak bosan dalam belajar dan untuk menarik perhatian siswa agar tidak kecanduan oleh gadget. Selain itu, guru juga memerlukan media pembelajaran yang menarik dan mampu merangsang minat siswa dalam belajar. Berdasarkan hasil observasi yang dilakukan di SD Gugus V Kecamatan Buleleng dapat diperoleh saat proses pembelajaran daring guru hanya memberikan tugas kepada siswa. Selain itu, kurangnya media pembelajaran yang membantu siswa belajar secara mandiri juga berdampak pada pemahaman siswa yang rendah.

Solusi untuk mengatasi permasalahan tersebut yaitu dengan mengembangkan media pembelajaran inovatif yang mampu meningkatkan pemahaman siswa. Berdasarkan hasil penyebaran kuesioner kepada guru kelas 1 di hasil 90\% guru sangat setuju menggunakan media pembelajaran dalam mengajar, $86 \%$ guru sangat setuju dalam mengajar guru menggunakan media pembelajaran yang bervariasi, 93\% guru sangat setuju saat menggunakan media pembelajaran siswa lebih bersemangat dalam belajar 93\% guru sangat setuju media pembelajaran dirancang dengan teknik belajar sambil bermain untuk mendukung pembelajaran tematik. Media pembelajaran adalah sarana yang dapat membantu siswa dalam belajar (Afifah, 2019; Putra, Handarini, \& Ramli, 2019; Wiastuti, Suadnyana, \& Kristiantari, 2014). Media pembelajaran yang bersifat konkret akan sangat mendukung pembelajaran di rumah karena menjadikan pembelajaran menjadi menyenangkan, bermakna, dan menghindari pengunaan gadget yang berlebihan serta menarik perhatian belajar siswa (Indriyani et al., 2019; Purwanti, 2015). Media konkret adalah media asli yang dapat membantu guru dalam menyampaikan informasi kepada anak sekolah. Media pembelajaran ini dapat dimanfaatkan dalam proses pembelajaran yang akan membangkitkan minat baru, motivasi, dan memberi pengaruh kepada psikologis siswa (Hadiyati \& Wijayanti, 2017; Khairunnisa \& Ilmi, 2020). Salah satu media yang dapat dimanfaatkan oleh guru di masa pandemic Covid-19 yaitu media fun thinkers. Media pembelajaran fun thinkers adalah media yang di desain dalam bentuk match frame yang disertai balok dengan angka dan warna dibelakang balok. Media ini juga dilengkapi buku dan terdapat lembar sial serta jawabannya. Sisi kiri dan kanan untuk lembar jawaban. Lembar soal dan jawaban yang diberikan berkaitan dengan pembelajaran tematik. Karakteristik media ini memuat level 10 materi yang berisi soal bahasa inggris dan matematika, namun yang dikembangkan pada penelitian ini adalah soal berbasis calistung yang cocok digunakan untuk siswa sekolah dasar sehingga mempermudah siswa untuk mempelajari pembelajaran dasar seperti membaca, menulis, serta berhitung. Pilar dari pembelajaran tematik yaitu calistung yang diyakini dapat meningkatkan serta menumbuhkan kemampuan berfikir sistematis dan logis pada siswa (Mulyadin, 2016; Ruiyat et al., 2019; Safitri et al., 2018).

Temuan penelitian sebelumnya menyatakan bahwa media konkret dapat memudahkan siswa memahami materi pembelajaran (Arianti et al., 2019a; Sutama et al., 2017). Temuan penelitian lainnya juga menyatakan bahwa media konkret dapat meningkatkan semangat dan hasil belajar siswa (Arianti et al., 2019a; Hadiyati \& Wijayanti, 2017). Belum adanya kajian mengenai media fun thinkers berbasis soal calistung karena pada umumnya media fun thinkers memuat latihan soal matematika dan bahasa Inggris. Media fun thinkers berbasis soal calistung yang dikembangkan berpedoman pada materi buku guru dan siswa kelas 1 tema 7 benda, hewan dan tanaman di sekitarku. Media ini terdiri dari buku dan alat peraga berbentuk match frame yang disertai balok kecil berukuran 4 x $4 \mathrm{~cm}$. Media ini terdiri dari sampul depan dan belakang, petunjuk penggunaan, daftar isi, kompetensi dasar dan indikator, bagian isi media yang memuat latihan soal. Kertas yang digunakan pada media fun thinkers ini adalah kertas berukuran A3 dan dibagi menjadi dua yaitu A4 pada lembar sisi kiri berupa soal dan lembar sisi kanan jawaban. Kelebihan media fun thinkers ini dikembangan berbeda dengan media fun thinkers seperti pada umumnya dengan ciri soal memuat materi soal berbasis calistung sehingga mempermudah siswa untuk mempelajarai buku 
tema, mengasah kemampuan calistung, menjadikan pembelajaran lebih bermakna, membangkitkan minat belajar siswa karena siswa diberikan pembelajaran secara langsung. Tujuan penelitian ini yaitu untuk menciptakan media fun thinkers berbasis soal calistung yang dapat meningkatkan kemampuan pembelajaran dasar (membaca, menulis dan berhitung). Diharapkan media pembelajaran ini dapat membantu siswa dalam belajar sehingga dapat meningkatkan pemahaman dan kemampuan calistung pada siswa.

\section{METODE}

Jenis penelitian ini yaitu penelitian pengembangan. Prosedur yang digunakan pada penelitian ini yaitu model ADDIE yang meliputi tahapan analisis, desain, pengembangan, implementasi, dan evaluasi (Rosmiati, 2019). Adapun desain pengembangan penelitian disajikan pada gambar 1. Subjek uji coba pada penelitian ini yaitu 2 orang ahli materi soal, 2 orang ahli media pembelajaran, 2 orang praktisi dan 7 orang siswa. Metode yang digunakan untuk mengumpulkan data pada penelitian ini adalah observasi dan kuesioner. Metode observasi dilakukan untuk mengumpulkan data mengenai permasalahan yang sedang terjadi di sekolah. Metode kuesioner digunakan untuk mengumpulkan data hasil penilaian yang diberikan oleh para ahli mengenai media yang dikembangkan. Instrumen pengumpulan data yang digunakan pada penelitian ini adalah rating scale. Instrumen ini digunakan untuk memperoleh data kuantitatif (angka/skor) yang kemudian dapat dijabarkan dalam kualitatif. Adapun kisi-kisi instrumen disajikan pada tabel 1, tabel 2, tabel 3 dan tabel 4 .

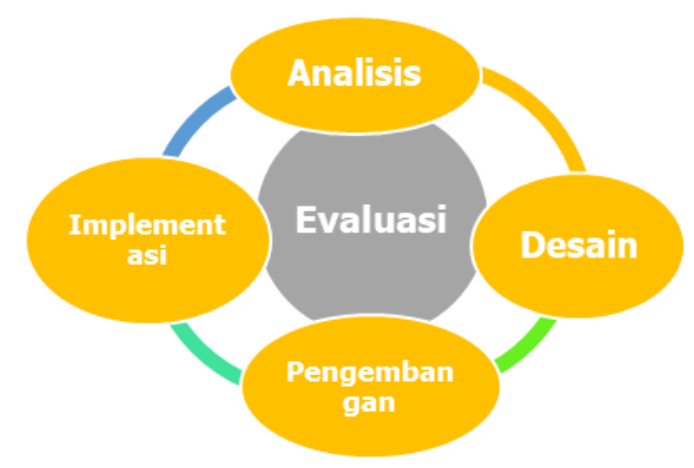

Gambar 1. Rancangan penelitian dengan Model ADDIE (Suryadi et al., 2020)

Tabel 1. Kisi-kisi Lembar Validasi Ahli Materi Soal Media Fun Thinkers

\begin{tabular}{lll}
\hline No & \multicolumn{1}{c}{ Aspek } & \multicolumn{1}{c}{ Indikator } \\
\hline \multirow{2}{*}{1} & \multirow{2}{*}{ Penggunaan Bahasa } & Kualitas penyusunan bahasa \\
& & Kualitas penggunaan kalimat \\
& & Relevansi materi soal terhadap kompetensi dasar \\
& \multirow{2}{*}{ Isi } & Relevansi materi soal terhadap indikator \\
& & Relevansi materi soal terhadap tingkat perkembangan siswa \\
& & Relevansi materi soal terhadap muatan calistung \\
& Penyajian soal & Tampilan soal \\
& & Kebenaran soal \\
\hline
\end{tabular}

(Ma'ratusholihah et al., 2019)

Tabel 2. Kisi-kisi Instrumen Validasi Ahli Media Media Fun Thinkers

\begin{tabular}{lll}
\hline No & \multicolumn{1}{c}{ Aspek } & \multicolumn{1}{c}{ Indikator } \\
\hline & & Desain sampul \\
1 & Desain Media & Penyajian gambar yang ditampilkan \\
& & Penyajian teks yang ditampilkan \\
2 & Penggunaan Bahasa & Penyajian warna yang ditampilkan \\
3 & Kemudahan Penggunaan Media & Kualitas penggunaan bahasa \\
\end{tabular}

(Mapicayanti et al., 2018) 
Tabel 3. Kisi-kisi Instrumen Respon Praktisi terhadap Media Fun Thinkers

\begin{tabular}{cll}
\hline No & \multicolumn{1}{c}{ Aspek } & \multicolumn{1}{c}{ Indikator } \\
\hline 1 & Tampilan & Kualitas tampilan media \\
2 & Bahasa & Kualitas penggunaan bahasa \\
3 & Isi & Kualitas isi media \\
4 & Kebertahanan media & Kebertahanan media \\
5 & Kemudahan Penggunaan Media & Kemudahan penggunaan media \\
\hline
\end{tabular}

Tabel 4. Kisi-kisi Instrumen Respon Siswa terhadap Media Fun Thinkers

\begin{tabular}{lll}
\hline No & \multicolumn{1}{c}{ Aspek } & \multicolumn{1}{c}{ Indkator } \\
\hline 1 & Tampilan & Kemenarikan tampilan media \\
2 & Bahasa & Kemudahan penggunaan bahasa \\
3 & Isi & Kualitas isi materi soal \\
4 & Kemudahan Penggunaan Media & Kemudahan penggunaa media \\
\hline
\end{tabular}

Validitas isi digunakan untuk mengetahui tingkat kevalidan kisi-kisi instrumen media yang disusun. Uji validitas ini dilakukan dengan menggunakan rumus Gregory. Pelaksanaan uji reliabilitas ini dilakukan melalui penilaian dari 2 orang ahli (judges) sesuai dengan bidang yang telah diuji. Rumus yang dapat digunakan untuk uji reliabilitas adalah percentage of agreement. Teknik analisis data yang digunakan pada penelitian ini yaitu analisis data deskriptif kualitatif dan kuantitatif. Pada analisis deskriptif kualitatif bersumber dari hasil review dari para ahli berupa kritik, tanggapan dan saran terhadap media pembelajaran yang dikembangkan. Analisis deskriptif kuantitatif digunakan untuk menganalisis penilaian (skor) dari uji coba produk dengan menggunakan rumus mean dan percentage of agreement.

\section{HASIL DAN PEMBAHASAN}

Hasil

Penelitian ini dilaksanakan dengan menggunakan model ADDIE yaitu salah satu model penelitian pengembangan yang terdiri dari beberapa tahapan yang dapat digunakan untuk mendesain dan mengembangkan sebuah program pelatihan secara efektif dan efisien. Tahapan tersebut yaitu analisis, desain, pengembangan, implementasi, dan evaluasi. Adapun hasil penelitian yaitu sebagai berikut. Tahap pertama yaitu analisis. Pada penelitian ini dilakukan dengan 4 langkah analisis yaitu analisis kurikulum, karakteristik siswa, kebutuhan dan media. Berdasarkan hasil analisis kebutuhan menunjukkan bahwa perlu adanya sebuah media pembelajaran yang mendukung untuk pembelajaran tematik sehingga dapat mendukung proses pembelajaran di kelas dan di rumah. Hasil analisis kurikulum yaitu menyusun indikator pencapaian kompetensi dasar, materi dan tujuan pembelajaran yang ingin dicapai. Analisis kurikulum yang dilaksanakan dapat dijadikan sebagai pedoman dalam mengembangkan media fun thinkers berbasis soal calistung. Adapun Kompetensi Dasar (KD) yang digunakan untuk mengembangkan media ini terdapat pada Tabel 5, Tabel 6, Tabel 7, Dan Tabel 8.

Tabel 5. Pemetaan KD Subtema 1 Benda Hidup dan Tak Hidup di Sekitar Kita

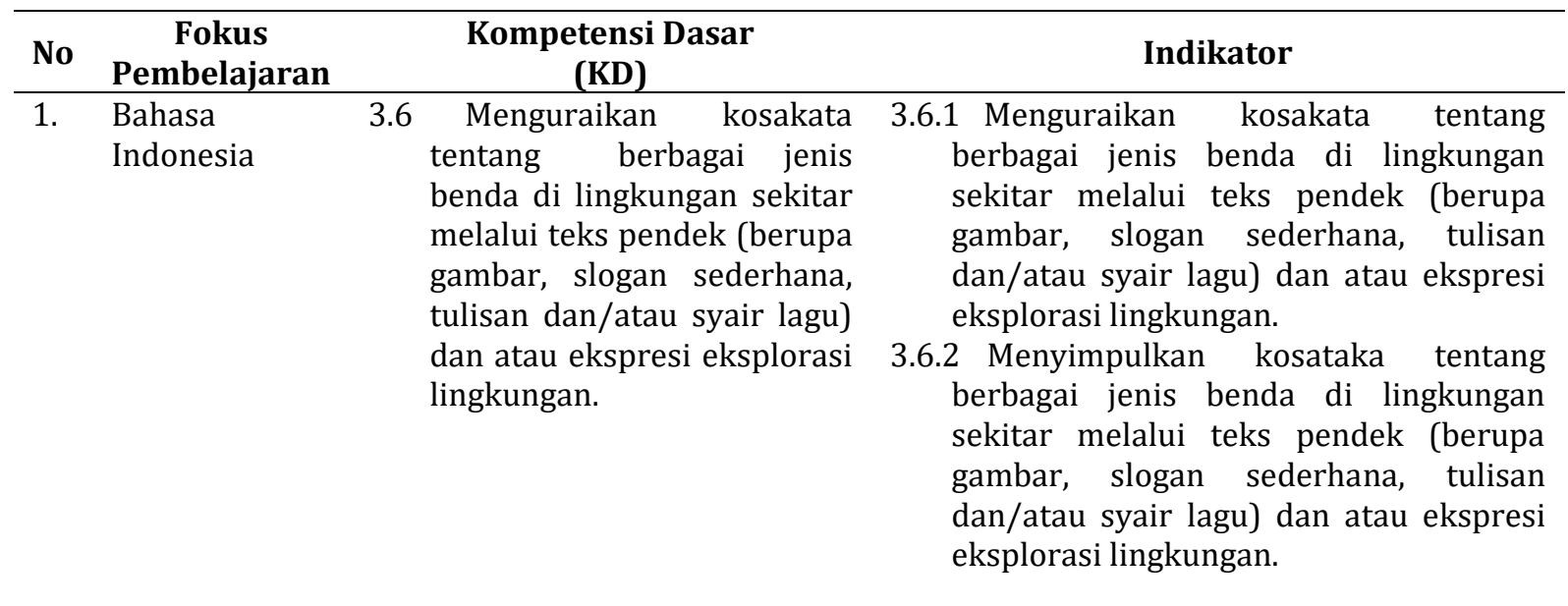




\begin{tabular}{|c|c|c|c|c|}
\hline No & $\begin{array}{c}\text { Fokus } \\
\text { Pembelajaran } \\
\end{array}$ & & $\begin{array}{c}\text { Kompetensi Dasar } \\
\text { (KD) }\end{array}$ & Indikator \\
\hline 2. & Matematika & 3.2 & $\begin{array}{l}\text { Menjelaskan bilangan } \\
\text { sampai dua angka dan nilai } \\
\text { tempat penyusun lambang } \\
\text { bilangan menggunakan } \\
\text { kumpulan benda konkret } \\
\text { serta cara membacanya. }\end{array}$ & $\begin{array}{l}\text { 3.2.1 Memilih bilangan dan penyusunannya } \\
\text { lambang bilangan menggunakan } \\
\text { kumpulan benda konkret serta cara } \\
\text { membacanya. } \\
\text { 3.2.2 Menjabarkan bilangan dua angka dan } \\
\text { nilai tempat penyusunannya lambing } \\
\text { bilangan menggunakan kumpulan benda } \\
\text { konret serta cara membacanya. }\end{array}$ \\
\hline 3. & PPKn & 3.1 & $\begin{array}{l}\text { Mengenal simbol sila-sila } \\
\text { Pancasila dalam lambang } \\
\text { Negara (Garuda Pancasila). }\end{array}$ & $\begin{array}{llr}\text { 3.1.1 Menemukann } & \text { simbol } & \text { sila-sila } \\
\text { Pancasila dalam } & \text { lambang } & \text { Negara } \\
\text { (Garuda Pancasila). } & & \end{array}$ \\
\hline 4. & PJOK & 3.6 & $\begin{array}{l}\text { Memahami gerak dasar } \\
\text { lokomotor dan non- } \\
\text { lokomotor sesuai dengan } \\
\text { iramaranas } \\
\text { tanpa/dengan musik dalam } \\
\text { aktivitas gerak berirama. }\end{array}$ & $\begin{array}{l}\text { 3.6.1 Memilih gerak dasar lokomotor dan } \\
\text { non-lokomotor sesuai dengan irama } \\
\text { (ketukan) tanpa/dengan musik dalam } \\
\text { aktivitas gerak berirama. }\end{array}$ \\
\hline
\end{tabular}

(Kemendikbud, 2017)

Tabel 6. Pemetaan KD Subtema 2 Hewan di Sekitarku

\begin{tabular}{|c|c|c|c|}
\hline No & $\begin{array}{c}\text { Fokus } \\
\text { Pembelajaran }\end{array}$ & $\begin{array}{c}\text { Kompetensi Dasar } \\
\text { (KD) }\end{array}$ & Indikator \\
\hline 1. & $\begin{array}{l}\text { Bahasa } \\
\text { Indonesia }\end{array}$ & $\begin{array}{l}\text { Merinci ungkapan } \\
\text { penyampaian terima kasih, } \\
\text { permintaan maaf, tolong dan } \\
\text { pemberian pujian, ajakan, } \\
\text { pemberitahuan, perintah dan } \\
\text { petunjuk kepada orang lain } \\
\text { dengan menggunakan bahasa } \\
\text { yang santun secara lisan dan } \\
\text { tulisan yang dapat dibantu } \\
\text { dengan kosakata bahasa daerah. }\end{array}$ & \begin{tabular}{lrr} 
3.8.1 Merinci & \multicolumn{2}{r}{ ungkapan } \\
penyampaian pemberitahuan \\
kepada orang lain dengan \\
menggunakan bahasa yang \\
santun secara lisan dan tulisan \\
yang dapat dibantu dengan \\
kosakata bahasa daerah.
\end{tabular} \\
\hline 2. & Matematika & $\begin{array}{l}\text { 3.3 Membandingkan dua bilangan } \\
\text { sampai dua angka dengan } \\
\text { menggunakan kumpulan benda- } \\
\text { benda konkret. }\end{array}$ & $\begin{array}{l}\text { 3.3.1 Mengurutkan bilangan sampai } \\
\text { dua } \\
\text { angka menggunakan kumpulan } \\
\text { benda konkret serta cara } \\
\text { membacanya. } \\
\text { 3.3.2 Membandingkan bilangan } \\
\text { sampai dua angka menggunakan } \\
\text { kumpulan benda konkret serta } \\
\text { cara membacanya. }\end{array}$ \\
\hline 3. & PPKn & $\begin{array}{l}\text { 3.2 Mengidentifikasi aturan yang } \\
\text { berlaku dalam kehidupan sehari- } \\
\text { hari di rumah. }\end{array}$ & $\begin{array}{l}\text { 3.2.1 Menentukan jenis-jenis hewan } \\
\text { peliharaan di rumah. } \\
\text { 3.2.2 Memilih aturan cara } \\
\text { merawat hewan peliharaan yang } \\
\text { berlaku dalam kehidupan sehari- } \\
\text { hari di rumah. }\end{array}$ \\
\hline
\end{tabular}

(Kemendikbud, 2017)

Tabel 7. Pemetaan KD Subtema 3 Tanaman di Sekitarku

\begin{tabular}{|c|c|c|c|}
\hline No & $\begin{array}{c}\text { Fokus } \\
\text { Pembelajaran }\end{array}$ & $\begin{array}{l}\text { Kompetensi Dasar } \\
\text { (KD) }\end{array}$ & Indikator \\
\hline 1. & $\begin{array}{l}\text { Bahasa } \\
\text { Indonesia }\end{array}$ & $\begin{array}{l}\text { 3.8 } \\
\text { Merinci }\end{array} \begin{array}{r}\text { ungkapan } \\
\text { penyampaian terima kasih, }\end{array}$ & $\begin{array}{l}\text { 3.8.1 Merinci ungkapan pemberian pujian } \\
\text { kepada orang lain dengan }\end{array}$ \\
\hline
\end{tabular}




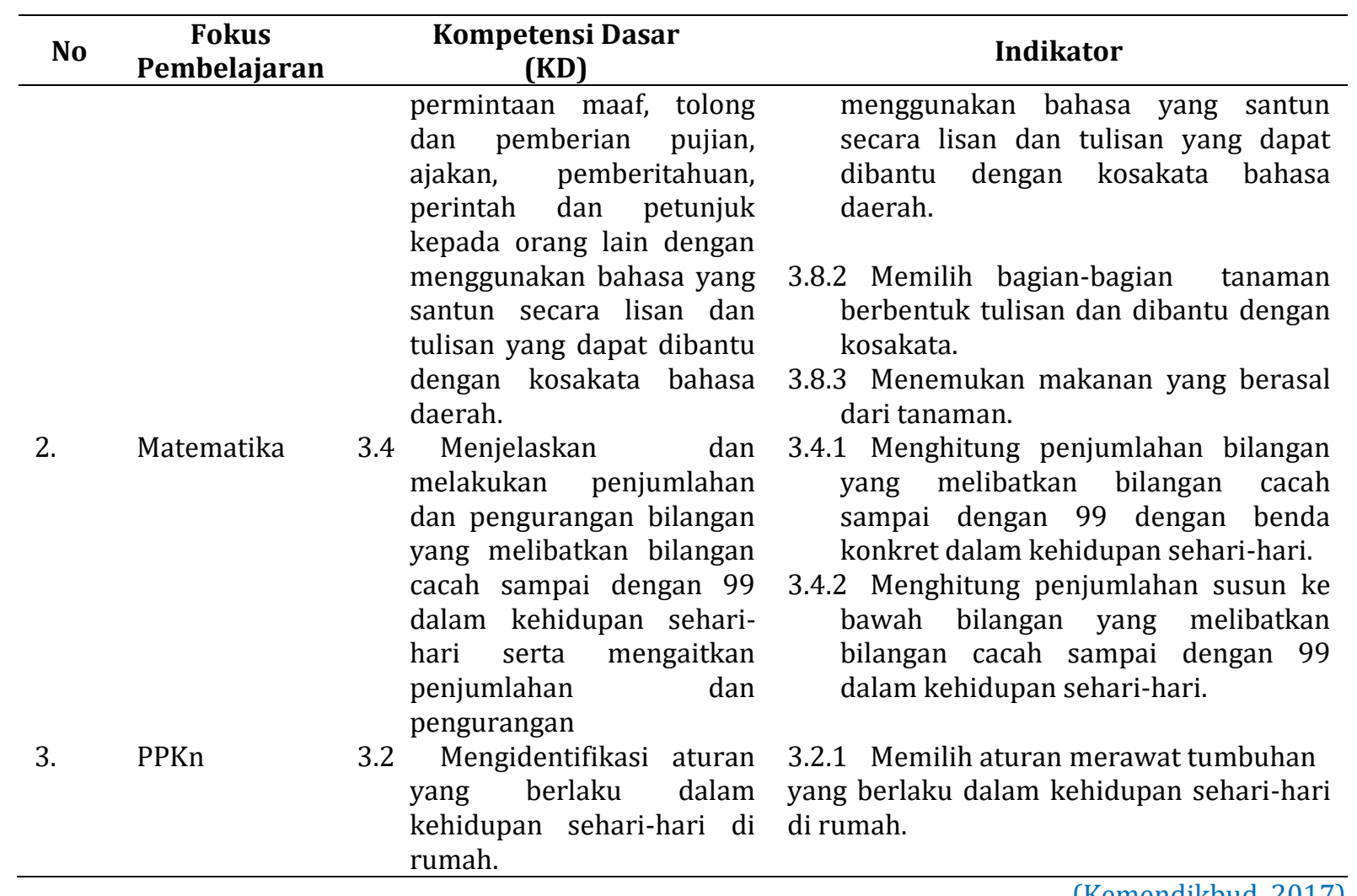

(Kemendikbud, 2017)

Tabel 8. Pemetaan KD Subtema 4 Bentuk, Warna, Ukuran dan Permukaan Benda

\begin{tabular}{|c|c|c|c|c|}
\hline No & $\begin{array}{c}\text { Fokus } \\
\text { Pembelajaran }\end{array}$ & & $\begin{array}{c}\text { Kompetensi Dasar } \\
\text { (KD) }\end{array}$ & Indikator \\
\hline 1. & $\begin{array}{l}\text { Bahasa } \\
\text { Indonesia }\end{array}$ & 3.6 & $\begin{array}{l}\text { Menguraikan } \\
\text { kosakata tentang } \\
\text { berbagai jenis benda di } \\
\text { lingkungan sekitar } \\
\text { melalui teks pendek } \\
\text { (berupa gambar, slogan } \\
\text { sederhana, tulisan } \\
\text { dan/atau syair lagu) } \\
\text { dan atau ekspresi } \\
\text { eksplorasi lingkungan }\end{array}$ & $\begin{array}{l}\text { 3.6.1 Menguraikan kosakata tentang } \\
\text { pengelompokkan benda berdasarkan } \\
\text { warna di lingkungan sekitar melalui teks } \\
\text { pendek (berupa gambar, slogan } \\
\text { sederhana, tulisan dan/atau syair lagu) } \\
\text { dan atau ekspresi eksplorasi lingkungan. } \\
\text { 3.6.2 Menentukan benda dan kegunaannya di } \\
\text { lingkungan sekitar melalui teks pendek } \\
\text { (berupa gambar, slogan sederhana, tulisan } \\
\text { dan/atau syair lagu) dan atau ekspresi } \\
\text { eksplorasi lingkungan. } \\
\text { 3.6.3 Memilih jenis-jenis permukaan benda di } \\
\text { lingkungan sekitar melalui teks pendek } \\
\text { (berupa gambar, slogan sederhana, tulisan } \\
\text { dan/atau syair lagu) dan atau ekspresi } \\
\text { eksplorasi lingkungan. } \\
\text { 3.6.4 Menentukan bentuk benda di } \\
\text { lingkungan sekitar melalui teks pendek } \\
\text { (berupa gambar, slogan sederhana, tulisan } \\
\text { dan/atau eskpresi eksplorasi lingkungan. } \\
\text { 3.6.5 Menentukan ukuran benda di } \\
\text { lingkungan sekitar melalui teks pendek } \\
\text { (berupa gambar, slogan sederhana, } \\
\text { Tulisan dan.atau ekspresi eksplorasi } \\
\text { lingkungan. }\end{array}$ \\
\hline 2. & Matematika & 3.2 & $\begin{array}{l}\quad \text { Menjelaskan } \\
\text { melakukan } \\
\text { penjumlahan }\end{array}$ & $\begin{array}{l}\text { 3.4.1 Menghitung pengurangan bilangan yang } \\
\text { melibatkan bilangan cacah sampai dengan } \\
99 \text { dengan benda konkret dalam }\end{array}$ \\
\hline
\end{tabular}




\begin{tabular}{|c|c|c|c|}
\hline No & $\begin{array}{c}\text { Fokus } \\
\text { Pembelajaran }\end{array}$ & $\begin{array}{c}\text { Kompetensi Dasar } \\
\text { (KD) }\end{array}$ & Indikator \\
\hline & & \begin{tabular}{lrr}
\multicolumn{2}{l}{ pengurangan } & bilangan \\
yang & melibatkan \\
bilangan cacah & sampai \\
dengan 99 & dalam \\
kehidupan & sehari-hari \\
serta & mengaitkan \\
penjumlahan & dan \\
pengurangan &
\end{tabular} & $\begin{array}{l}\text { kehidupan sehari-hari. } \\
\text { 3.4.2 Menghitung pengurangan susun ke } \\
\text { bawah bilangan yang melibatkan bilangan } \\
\text { cacah sampai dengan } 99 \text { dalam kehidupan } \\
\text { sehari-hari. }\end{array}$ \\
\hline
\end{tabular}

(Kemendikbud, 2017)

Hasil analisis karakteristik siswa yaitu, diperoleh hasil bahwa anak pada usia 7-11 tahun atau usia SD mengalami tahap operasional konkret I yang membutuhkan pembelajaran dengan hal-hal yang bersifat konkret, nyata dan dapat diamati secara langsung oleh siswa. Berdasarkan hasil analisis media yaitu kriteria yang baik dapat dilihat dari keefektifan, efisiensi, dan komunikatif media. Tahap kedua yaitu perancangan. Pada tahap ini dilakukan dengan menyusun instrumen media dan rancangan pengembangan media fun thinkers berbasis soal calistung. Selain itu, pada tahap ini merancang media media fun thinkers berbasis soal calistung yang dikembangkan dengan pedoman materi buku guru dan siswa kelas 1 tema 7 benda, hewan dan tanaman di sekitarku. Media fun thinkers berbasis soal calistung diperuntukkan untuk siswa kelas 1 sekolah dasar. Perangkat lunak yang digunakan untuk merancang media ini adalah aplikasi Corel Draw X7 untuk mendesain layout dan aplikasi Photoshop untuk mengedit gambar. Perancangan media ini dimulai dari merancang cover depan dan belakang media fun thinkers, menyusun soal berdasarkan KD, materi, indikator dan tujuan yang ingin dicapai pada isi buku media fun thinkers serta merancang desain tampilan isi pada media fun thinkers. Kertas yang digunakan dalam merancang media fun thinkers ini adalah kertas berukuran A3 dan dibagi menjadi dua yaitu A4 pada sisi kiri berupa soal dan sisi kanan jawaban. Media disajikan dalam bentuk hardcopy dan lengkap dengan alat peraganya. Adapun hasil rancangan media disajikan pada gambar 1.

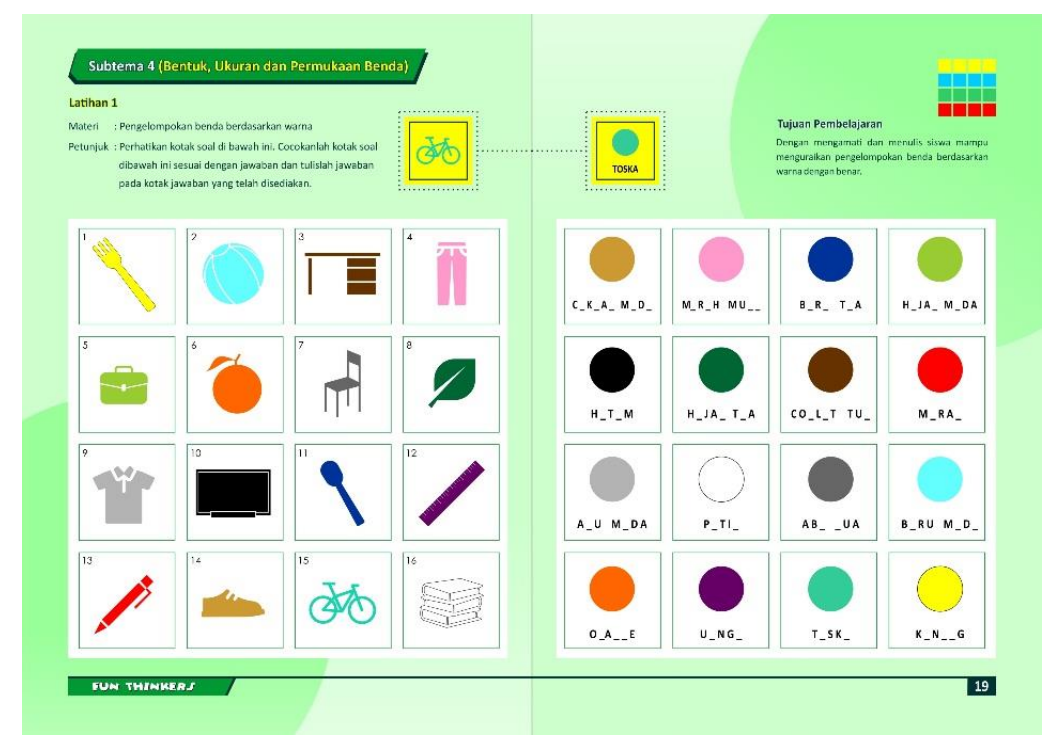

Gambar 1. Rancangan Media Fun Thinkers

Tahap ketiga yaitu pengembangan. Pelaksanaan tahap pengembangan (development) dilakukan dengan mengembangkan produk yang sebenarnya sesuai dengan hasil analisis dan perancangan. Sampul media fun thinkers ini didesain dengan background berwarna hijau dengan gambar menyesuaikan dengan buku siswa kelas 1 tema 7 benda, hewan dan tanaman di sekitaku. Ukuran font yang digunakan menyesuaikan dengan ukuran sampul agar terlihat jelas dan mudah dibaca. Adapun hasil produk yang dikembangkan disajikan pada gambar 2 . 

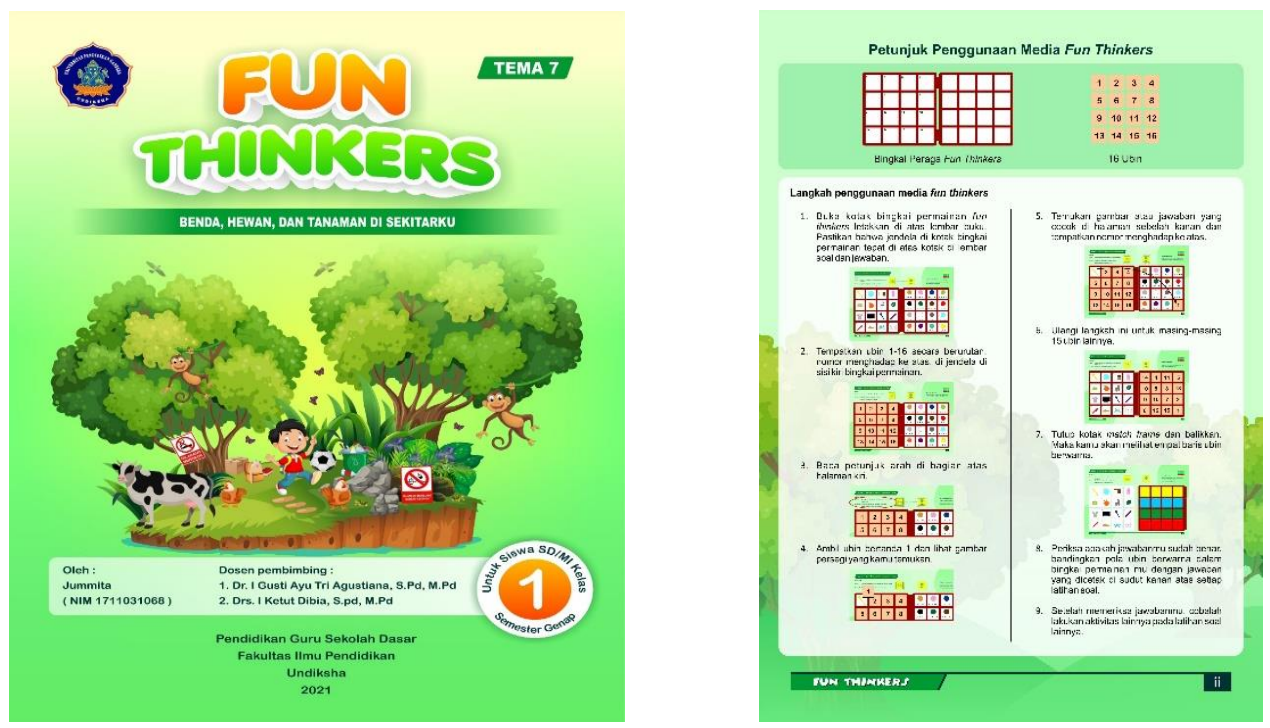

Gambar 2. Hasil Pengembangan Media Fun Thinkers Berbasis Soal Calistung

Setelah media Fun Thinkers berbasis soal calistung dikembangkan, selanjutnya dilakukan penilaian terhadap produk tersebut oleh para ahli dan praktisi serta siswa untuk mengetahui validitas media yang dikembangkan. Selain itu penilain ini dilakukan untuk memperoleh komentar berupa saran dan kritik guna perbaikan terhadap media yang dikembangkan agar media menjadi media yang layak digunakan untuk proses pembelajaran. Adapun hasil penilaian disajikan pada tabel 9.

Tabel 9. Hasil Penilaian Produk Fun Thinkers

\begin{tabular}{clcc}
\hline No & \multicolumn{1}{c}{ Para Ahli } & Nilai & Kategori \\
\hline 1 & Ahli Materi Soal & 4,63 & Sangat valid \\
2 & Ahli Media Pembelajaran & 4,82 & Sangat valid \\
3 & Hasil Uji Respon Praktisi & 4,85 & Sangat valid \\
4 & Hasil Uji Respon Siswa & 4,95 & Sangat valid \\
\hline
\end{tabular}

Berdasarkan hasil penilaian yang diberikan oleh ahli materi soal, media yang dikembangkan mendapatkan nilai 4,63 sehingga mendapatkan kategori sangat valid. Hasil penilaian yang diberikan oleh ahli media pelajaran, media yang dikembangkan mendapatkan nilai 4,82 sehingga mendapatkan kategori sangat valid. Hasil penilaian yang diberikan oleh respon praktisi, media yang dikembangkan mendapatkan nilai 4,85 sehingga mendapatkan kategori sangat valid. Hasil penilaian yang diberikan oleh uji respon siswa media yang dikembangkan mendapatkan nilai 4,95 sehingga mendapatkan kategori sangat valid. Adapun saran yang diberikan oleh para ahli untuk menyempurnakan produk media fun thinkers berbasis soal calistung yang telah dikembangkan yaitu; beri jarak antara pembeda huruf dengan spasi dan tanpa spasi, dan pemberian contoh gambar yang mudah dikenali siswa. Adapun hasil revisian produk disajikan pada gambar 3 .

Berdasarkan hasil analisis data, maka dapat disimpulkan bahwa produk media fun thinkers berbasis soal calistung mendapatkan kategori sangat valid sehingga layak diterapkan dalam proses pembelajaran. Media yang di kembangkan dikembangkan sesuai dengan analisis kebutuhan yang telah dilakukan. Berdasarkan analisis kebutuhan yang dilakukan untuk mengetahui kebutuhan dari guru dan siswa dalam proses pembelajaran dilakukan penyebaran kuesioner kepada guru kelas 1 di SD Gugus V Kecamatan Buleleng terkait media yang di kembangkan, diperoleh hasil bahwa guru sangat setuju untuk mengembangkan media fun thinkers berbasis soal calistung yang akan dapat mendukung proses pembelajaran tematik dan pembelajaran yang di lakukan di rumah dan di kelas. Oleh karena tu, media fun thinkers berbasis soal calistung dikembangkan agar bisa membantu guru dan siswa pada proses pembelajaran. Media ini juga akan memudahkan siswa dalam memahami materi pembelajaran maka akan memberikan dampak pada hasil belajar siswa. 


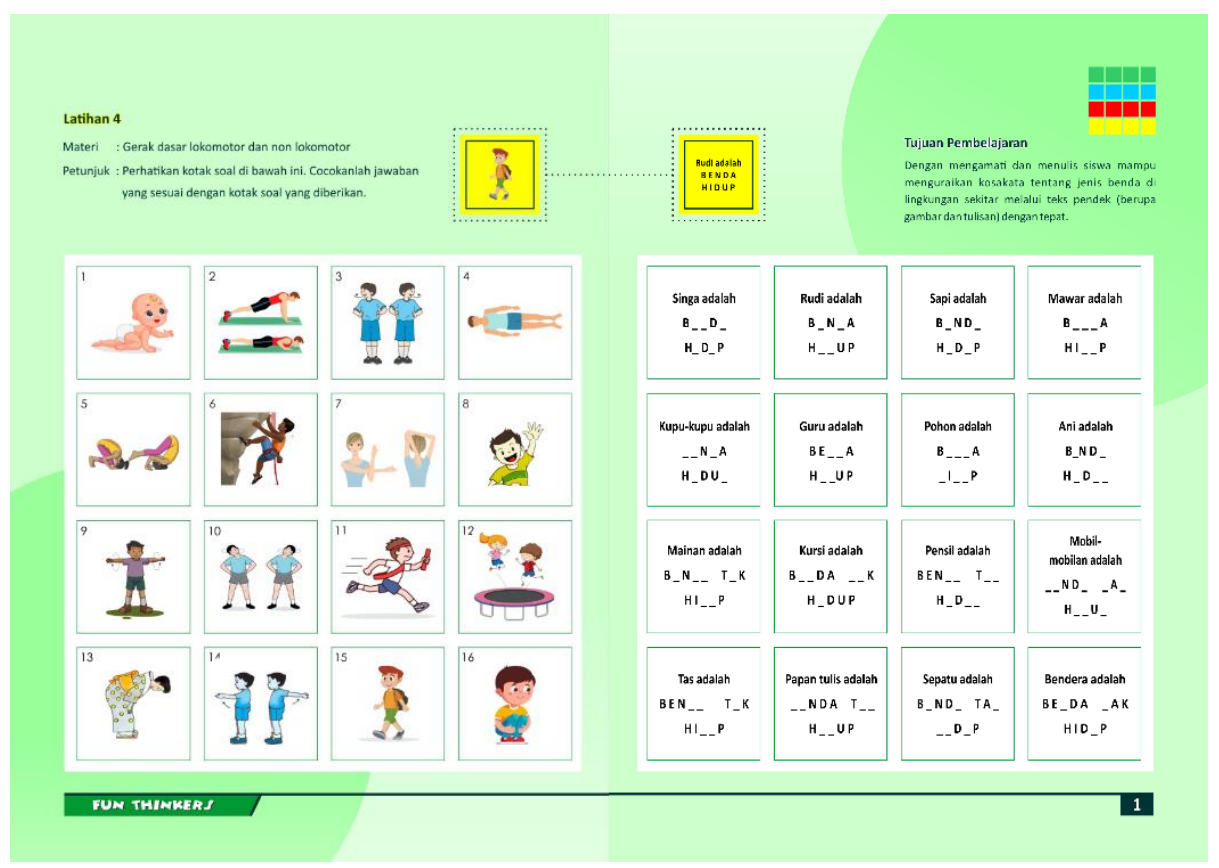

Gambar 3. Hasil Revisian Media Fun Thinkers Berbasis Soal Calistung

Media Pembelajaran Fun Thinkers berbasis soal calistung layak diterapkan dalam proses pembelajaran disebabkan oleh beberapa faktor yaitu sebagai berikut. Pertama, media pembelajaran fun thinkers berbasis soal calistung layak diterapkan dalam proses pembelajaran disebabkan karena dapat merangsang kemauan siswa dalam belajar. Media Fun Thinkers berbasis soal calistung yang dikembangkan menarik minat dan perhatian siswa. Hal ini disebabkan karena kualitas tampilan media yang sangat baik. Tampilan media yang menarik dapat meningkatkan semangat siswa dalam belajar (Hosen et al., 2021; Khofiyah et al., 2019; Prasasti et al., 2019). Selain itu, media ini juga menggunakan kualitas bahasa yang baik sehingga memudahkan siswa belajar. Kualitas bahasa yang baik akan membuat siswa semakin terangsang dan meningkatkan minat siswa dalam belajar (Herawati \& Muhtadi, 2018; Lee \& Osman, 2012; Neppala et al., 2018; Ricu Sidiq, 2020).

Kemudahan penggunaan media ini juga dapat meningkatkan semangat siswa dalam belajar. Media pembelajaran ini didesain berbentuk match frame yang disertai dengan balok yang berisikan warna dan angka dibelakang balok sehingga meningkatkan minat belajar siswa. Media Fun Thinkers memiliki unsur yang menyenangkan dalam bentuk permainan sehingga siswa tidak bosan dalam belajar. Belajar sambal bermain akan membuat siswa merasa senang dalam belajar dan termotivasi untuk belajar (Nurani \& Mayangasri, 2017; Puspitasari \& Murda, 2018; Utomo et al., 2018). Media fun thinkers ini dilengkapi dengan buku yang sudah berisi langsung petunjuk penggunaanya sehingga memudahkan siswa untuk menggunakannya. Media pembelajaran ini juga dapat menekankan keterlibatan siswa secara aktif dalam proses pembelajaran sehingga dapat melatih anak dan menemukan pengetahuannya sendiri. Pengembangan kreativitas dan inovasi untuk membuat media fun thinkers berbasis soal calistung pada kelas 1 SD tema 7 benda, hewan dan tanaman di sekitarku yang akan mempermudah pembelajaran dasar (membaca, menulis dan berhitung) dalam pembelajaran tematik dan menyeimbangkan pembelajaran daring atau jarak jauh agar siswa tidak hanya berpacu pada media Tekonologi Informasi melalui alat penunjang gadget serta menjadikan pembelajaran di rumah lebih menyenangkan.

Kedua, media pembelajaran fun thinkers berbasis soal calistung layak diterapkan dalam proses pembelajaran disebabkan karena memudahkan siswa dalam memahami materi pelajaran. Media fun thinkers merupakan media yang bersifat nyata dan konkret. Media pembelajaran konkret akan memudahkan siswa dalam memahami materi yang disajikan pada media (Arianti et al., 2019b; Carlucy et al., 2018). Media pembelajarna konkret juga dapa membantu guru dalam menerangkan materi pembelajaran (Arianti et al., 2019b; Sutama et al., 2017). Hal ini sesuai dengan teori Piaget yang menyatakan bahwa anak usia 7-11 tahun atau usia SD mengalami tahap operasional konkret I yang membutuhkan pembelajaran melalui pengalaman dengan hal-hal yang bersifat konkret, nyata dan dapat diamati secara langsung oleh siswa (Carlucy et al., 2018; Prabaningrum \& Putra, 2019). Media fun thinkers berbasis soal calistung dapat mempermudah siswa untuk mempelajari pembelajaran dasar yaitu membaca, menulis dan berhitung yang diyakini dapat meningkatkan kemampuan berfikir logis dan siswa tematis siswa, meningkatkan keterampilan peserta didik dalam merefleksikan pikiran dan idenya. Siswa 
yang mampu membaca, menulis dan berhitung dengan baik akan cenderung dapat lebih mengerti dan dapat mengikuti pembelajaran dengan baik.

Temuan penelitian sebelumnya menyatakan bahwa media pembelajaran dapat meningkatkan pemahaman siswa terhadap materi pelajaran (Fatmawati \& Harmanto, 2019; Linda et al., 2018; Primasari, 2014). Temuan penelitian lainnya juga menyatakan bahwa penggunaan media pembelajaran dapat meningkatkan hasil belajar siswa (Dewi, Kristiantari, \& Ganing, 2019; Hanifah \& Budiman, 2019; Putra \& Sujana, 2020). Kelebihan media media fun thinkers ini dikembangan berbeda dengan media fun thinkers seperti pada umumnya dengan ciri soal memuat materi soal bahasa Inggris dan matematika, karena media fun thinkers yang dikembangkan berbasis soal calistung untuk siswa SD kelas 1 pada tema 7 benda, hewan dan tanaman di sekitarku. Penelitian ini berkontribusi pada peningkatan semangat belajar siswa. Keterbatasan penelitian ini yaitu penelitian ini hanya dilakukan pada uji kelompok kecil, hal ini dikarenakan adanya pandemic Covid-19. Penelitian selanjutnya diharapkan dapat melajutkan penelitin ini melalui eksperimen dengan jumlah siswa lebih banyak. Implikasi penelitian ini yaitu media fun thinkers berbasis soal calistung untuk siswa SD kelas 1 pada tema 7 benda, dapat digunakan oleh guru dan siswa dalam proses pembelajaran. Penggunaan media ini akan membantu guru untuk menyampaikan materi, membantu siswa untuk mempelajari dan mengasah kemampuan dasar membaca, menulis dan berhitung, selain itu juga mempermudah siswa untuk memahami materi dengan belajar sambil bermain.

\section{SIMPULAN}

Media fun thinkers berbasis soal calistung yang dikembangkan mendapatkan kategori sangat baik sehingga dapat dan layak digunakan dalam proses pembelajaran. direkomendasikan kepada guru untuk menggunakan media fun thinkers berbasis soal calistung karena dapat membantu siswa dalam belajar dan mengasah kemampuan dasar pada siswa.

\section{DAFTAR PUSTAKA}

Abidah, A., Hidaayatullaah, H. N., Simamora, R. M., Fehabutar, D., \& Mutakinati, L. (2020). The Impact of Covid-19 to Indonesian Education and Its Relation to the Philosophy of "Merdeka Belajar." Studies in Philosophy of Science and Education, 1(1), 38-49. /https://doi.org/10.46627/sipose.v1i1.9.

Afifah, N. (2019). Efektivitas Media Ajar untuk Siswa Kelas Rendah Berbasis Nilai Karakter Toleransi terhadap Sesama dengan Berbantu Aplikasi Sparkol Videoscribe. Modeling: Jurnal Program Studi PGMI, 6(2). https://doi.org/10.36835/modeling.v6i2.512.

Aji, R. H. S. (2020). Dampak Covid-19 pada Pendidikan di Indonesia: Sekolah, Keterampilan, dan Proses

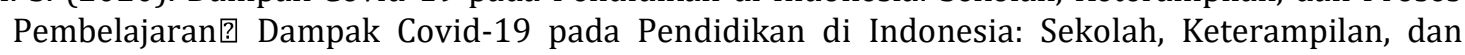
Proses Pembelajaran. Jurnal Sosial \& Budaya Syar-I, 5(1), 395-402. https://doi.org/10.15408/sjsbs.v7i5.15314.

Arianti, Wiarta, \& Darsana. (2019a). Pengaruh Model Pembelajaran Problem Posing Berbantuan Media Semi Konkret terhadap Kompetensi Pengetahuan Matematika. Jurnal Ilmiah Sekolah Dasar Undiksha, 3(4). http://dx.doi.org/10.23887/jisd.v3i4.21765.

Arianti, Wiarta, \& Darsana. (2019b). Pengaruh Model Pembelajaran Problem Posing Berbantuan Media Semi Konkret terhadap Kompetensi Pengetahuan Matematika. Jurnal Ilmiah Sekolah Dasar, 3(4). https://doi.org/10.23887/jisd.v3i4.21765.

Ariebowo, T. (2021). Autonomous learning during COVID-19 pandemic: Students' objectives and preferences. Journal of Foreign Language Teaching and Learning, 6(1), 56-77. https://doi.org/https://doi.org/10.18196/ftl.v6i1.10079.

Atmojo, A. E. P., \& Nugroho, A. (2020). EFL classes must go online! Teaching activities and challenges during COVID-19 pandemic in Indonesia. Register Journal, 13(1), 49-76. https://doi.org/https://doi.org/10.18326/rgt.v13i1.49-76.

Ayuni, D., Marini, T., Fauziddin, M., \& Pahrul, Y. (2021). Kesiapan Guru TK Menghadapi Pembelajaran Daring Masa Pandemi Covid-19. Jurnal Obsesi: Jurnal Pendidikan Anak Usia Dini, 5(1). https://doi.org/https://doi.org/10.31004/obsesi.v5i1.579.

Baber, H. (2021). Modelling the acceptance of e-learning during the pandemic of COVID-19-A study of South Korea. The International Journal of Management Education, 19(2). https://doi.org/10.1016/j.ijme.2021.100503.

Baiduri, Marhan, \& Lufita. (2019). Pengembangan media pembelajaran pop-up book berbasis audio pada materi bangun datar segiempat. Jurnal Program Studi Pendidikan Matematika, 8(1). http://dx.doi.org/10.24127/ajpm.v8i1.1951.

Carlucy, Suadnyana, \& Negara. (2018). Pengaruh Model Pembelajaran Inkuiri Terbimbing Berbantuan 
Media Konkret Terhadap Kompetensi Pengetahuan IPA. Mimbar Ilmu Undiksha, 23(2), 162-169. https://doi.org/10.23887/mi.v23i2.16416.

Dewi, N. N. K., Kristiantari, M. . R., \& Ganing, N. N. (2019). Pengaruh Model Pembelajaran Picture And Picture Berbantuan Media Visual Terhadap Keterampilan Menulis Bahasa Indonesia. Journal of Education Technology, 3(4). http://dx.doi.org/10.23887/jet.v3i4.22364.

Dewi, W. A. F. (2020). Dampak COVID-19 Terhadap Implementasi Pembelajaran Daring Di Sekolah Dasar. Jurnal Ilmu Pendidikan, 2(1), 55-61. https://edukatif.org/index.php/edukatif/index.

Fatmawati, F., \& Harmanto. (2019). Pengembangan Media Puzzle Berbasis Index Card Match Materi Peristiwa Lahirnya Pancasila Muatan IPS. Joyful Learning Journal, 8(2), 113-118. https://doi.org/10.15294/jlj.v8i2.

Hadiyati, N., \& Wijayanti, A. (2017). Keefektifan Metode Eksperimen Berbantu Media Benda Konkret Terhadap Hasil Belajar IPA Siswa Kelas V Sekolah Dasar. JIPVA (Jurnal Pendidikan IPA Veteran), 1(1). https://doi.org/10.31331/jipva.v1i1.513.

Hanifah, \& Budiman. (2019). Pengaruh Model Open Ended Problem Berbantu Media Kotak Telur Pelangi ( Kotela ) Terhadap Hasil Belajar. Journal of Education Technology., 3(3), 1137.http://dx.doi.org/10.23887/jet.v3i3.21734.

Hendriawan, M. A., \& Septian, A. (2019). Pengembangan JiMath Sebagai Multimedia Pembelajaran Matematika Berbasis Android Untuk Siswa Sekolah Menengah Atas. IndoMath: Indonesia Mathematics Education, 2(1), 45. https://doi.org/10.30738/indomath.v2i1.2785.

Herawati, N. S., \& Muhtadi, A. (2018). Pengembangan Modul Elektronik (E-Modul) Interaktif Pada Mata Pelajaran Kimia kelas XI SMA. Jurnal Inovasi Teknologi Pendidikan, 5(2), 180-191. https://doi.org/10.21831/jitp.v5i2.15424.

Hosen, M., Ogbeibu, S., Giridharan, B., Cham, T.-H., Lim, W. M., \& Paul, J. (2021). Individual motivation and social media influence on student knowledge sharing and learning performance: Evidence from an emerging economy. Computers \& Education, 72. https://doi.org/10.1016/j.compedu.2021.104262.

Indriyani, D., Mawardi, M., \& Wardani, K. W. (2019). Peningkatan Keterampilan Berpikir Kritis Melalui Model Inkuiri Berbantuan Media Konkret Pada Siswa Kelas 5 SD Negeri Mangunsari 05 Tahun Pelajaran 2018/2019. Jurnal Basicedu, 3(1). https://doi.org/10.31004/basicedu.v3i1.74.

Kemendikbud. (2017). Buku Tematik Terpadu Kurikulum 2013.

Khairunnisa, G. F., \& Ilmi, Y. I. N. (2020). Media Pembelajaran Matematika Konkret Versus Digital: Systematic Literature Review di Era Revolusi Industri 4.0. Jurnal Tadris Matematika, 3(2). https://doi.org/10.21274/jtm.2020.3.2.131-140.

Kharisma Bismi Alrasheed, \& Aprianti, M. (2011). Hubungan Antara Kecanduan Gadget Dengan Kecerdasan Emosi Pada Remaja (Sebuah Studi Pada Siswa Smp Di Kecamatan Setiabudi Jakarta $\begin{array}{lllll}\text { Selatan). Jurnal Sains } & \text { Psikologi, } & \text { 136-142. }\end{array}$ http://dx.doi.org/10.17977/um023v7i22018p136.

Khofiyah, H. N., Santoso, A., \& Akbar, S. (2019). Pengaruh Model Discovery Learning Berbantuan Media Benda Nyata terhadap Kemampuan Berpikir Kritis dan Pemahaman Konsep IPA. Jurnal Pendidikan: Teori, Penelitian, Dan Pengembangan, 4(1), 61-67. http://dx.doi.org/10.17977/jptpp.v4i1.11857.

Lee, T. T., \& Osman, K. (2012). Interactive Multimedia Module in the Learning of Electrochemistry: Effects on Students' Understanding and Motivation. Procedia - Social and Behavioral Sciences, 46, $1323-$ 1327. https://doi.org/10.1016/j.sbspro.2012.05.295.

Lilawati, A. (2020). Peran Orang Tua dalam Mendukung Kegiatan Pembelajaran di Rumah pada Masa Pandemi. Jurnal Obsesi: Jurnal Pendidikan Anak Usia Dini, 5(1), 549. https://doi.org/10.31004/obsesi.v5i1.630.

Linda, Albeta, Masnaini, \& Sulismawati. (2018). The Effect Of Prezy And Exe-Learning Media On Chemical Learning Results. Jurnal Edusains, 10(1). https://doi.org/10.15408/es.v10i1.7204.

Ma'ratusholihah, Priyanto, \& Damayani, A. . (2019). Pengembangan media pembelajaran tematik ular

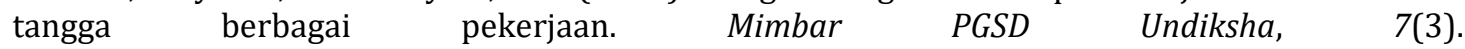
http://dx.doi.org/10.23887/jjpgsd.v7i3.19411.

Mapicayanti, Jamaludin, \& Ahmad, F. (2018). Perancangan media pembelajaran berbasis video tutorial mendesain jaringan lokal/LAN kelas X TKJ. Jurnal Pendidikan Informatika, 2(2). https://doi.org/10.29408/edumatic.v2i2.913.

Mulyadin. (2016). Mulyadin. (2016). Implementasi Kebijakan Pembelajaran Tematik Terpadu Kurikulum 2013 Di SDN Kauman 1 Malang Dan Sd Muhammadiyah 1 Malang. Jurnal Pendidikan Edutama, 3(2), 31 - 48. https://doi.org/10.30734/jpe.v3i2.35.

Neppala, P., Sherer, M. V., Larson, G., Bryant, A. K., Panjwani, N., Murphy, J. D., \& Gillespie, E. F. (2018). An 
interactive contouring module improves engagement and interest in radiation oncology among preclinical medical students: Results of a randomized trial. Practical Radiation Oncology, 8(4), e190-e198. https://doi.org/10.1016/j.prro.2018.01.001.

Nurani, Y., \& Mayangasri, T. (2017). Pengembangan Model Kegiatan Sentra Bermain Dalam Mengembangkan Kreativitas Anak Usia Dini. Jurnal Pendidikan Usia Dini, 11(2). https://doi.org/10.21009/JPUD.112.15.

Ompi, Sompie, \& Sugiarso. (2020). Video animasi interaktif 3d dampak penggunaan gadget pada anak sekolah dasar tingkat awal. Jurnal Teknik Elektro Dan Komputer, 9(2). https://doi.org/10.35793/jtek.9.2.2020.29717.

Pebriana, P. H. (2017). Analisis Penggunaan Gadget Terhadap Kemampuan Interaksi Sosial Anak Usia Dini. Jurnal Obsesi: Journal of Early Childhood Education, 1(1). https://doi.org/10.31004/obsesi.v1i1.26.

Prabaningrum, \& Putra. (2019). Pengaruh Model Pembelajaran Kooperatif Team Assisted Individualization Berbantuan Media Semi Konkret Terhadap Kompetensi Pengetahuan Matematika. Jurnal Ilmiah Sekolah Dasar, 3(4), 414. https://doi.org/10.23887/jisd.v3i4.21775.

Prasasti, T. I., Solin, M., \& Hadi, W. (2019). The Effectiveness of Learning Media Folklore Text of North Sumatera Based on Blended Learning by 10th Grade Students of Vocational High SchoolHarapan Mekar-1 Medan. Bir-Le Journal, 4(2). https://doi.org/10.33258/birle.v2i4.548.

Primasari, R. (2014). Penggunaan Media Pembelajaran di Madrasa Aliyah Negeri Se-Jakarta Selatan. Edusains, 6(1), 68-72. https://doi.org/https://doi.org/10.15408/es.v6i1.1101.

Purwanti, K. L. (2015). Pembelajaran Perkalian Pecahan Biasa Berbantu Media Benda Konkret: Studi Kasus Perbedaan Gender Terhadap Kemampuan Matematika Siswa Kelas V SDN Sambiroto 3 Semarang. Sawwa: Jurnal Studi Gender, 5(2). https://doi.org/10.21580/sa.v10i2.1431.

Puspitasari, \& Murda. (2018). Pengaruh Model Pembelajaran IOC Berbantuan Media Audio Visual terhadap Hasil Belajar IPS. Mimbar PGSD Undiksha, 6(2). http://dx.doi.org/10.23887/jjpgsd.v6i2.19470.

Putra, A. T., Handarini, D. M., \& Ramli, M. (2019). Media Wayang Golek untuk Menumbuhkan Kesadaran Menyelesaikan Konflik secara Konstruktif bagi Siswa SMP. Jurnal Pendidikan: Teori, Penelitian, Dan Pengembangan, 4(11). /https://doi.org/10.17977/jptpp.v4i11.13006.

Putra, I. G. D. (2020). Hasil belajar IPS menggunakan Kolaborasi Model Discovery Learning Berbasis Media Animasi. 4, 103-109.

Ricu Sidiq, \& N. (2020). Pengembangan E-Modul Interaktif Berbasis Android pada Mata Kuliah Strategi Belajar Mengajar. Jurnal Pendidikan Sejarah, 9(1), 1-14. https://doi.org/10.21009/JPS.091.01.

Rosmiati, M. (2019). Animasi Interaktif Sebagai Media Pembelajaran Bahasa Inggris Menggunakan Metode ADDIE. Paradigma: Jurnal Komputer Dan Informatika Univiersitas Bina Sarana Informatika, 21(2). https://doi.org/10.31294/p.v21i2.6019.

Ruiyat, S. A., Yufiarti, Y., \& Karnadi, K. (2019). Peningkatan Keterampilan Berbicara dengan Bercerita Menggunakan Komik Elektronik Tematik. Jurnal Obsesi : Jurnal Pendidikan Anak Usia Dini, 3(2). https://doi.org/10.31004/obsesi.v3i2.256.

Safitri, R. W., Primiani, C. N., \& Hartini, H. (2018). Pengembangan Media Flashcard Tematik Berbasis Permainan Tradisional Untuk Kelas IV Sub Tema Lingkungan Tempat Tinggalku. Pendidikan Dasar Dan Pembelajaran, 8(1), 11. http://doi.org/10.25273/pe.v8i1.1332.

Shaik Alavudeen, S., Easwaran, V., Iqbal Mir, J., Shahrani, S. M., Ali Aseeri, A., Abdullah Khan, N., Mohammed Almodeer, A., \& Abdullah Asiri, A. (2021). The influence of COVID-19 related psychological and demographic variables on the effectiveness of e-learning among health care students in the southern region of Saudi Arabia. Saudi Pharmaceutical Journal. https://doi.org/10.1016/j.jsps.2021.05.009.

Suastika, I. K., \& Amaylyla. (2019). Pengembangan modul pembelajaran matematika dengan pendekatan kontekstual. Jurnal Pendidikan Matematika Indonesia, 4(2). https://dx.doi.org/10.26737/jpmi.v4i2.1230.

Suryadi, I., Yanto, Y., \& Mandasari, N. (2020). Pengembangan Media Pembelajaran Interaktif Berbasis Pmri Menggunakan Macromedia Flash Profesional 8. Judika Education, 3(2), 40-49. https://doi.org/10.31539/judika.v3i1.1263.

Sutama, I. P. E., Dibia, I. K., \& Margunayasa, I. G. (2017). Pengaruh Model Pembelajaran Think Pair Share (TPS) Berbantuan Media Konkret Terhadap Hasil Belajar IPA. MIMBAR PGSD Undiksha, 5. http://dx.doi.org/10.23887/jjpgsd.v5i2.10683.

Utomo, I. A., Ramli, M., \& Furaidah, F. (2018). Penerapan Strategi Bermain melalui Media Busy Book untuk Meningkatkan Fisik Motorik Halus Anak Usia Dini. Jurnal Pendidikan: Teori, Penelitian, Dan Pengembangan, 3(12). https://doi.org/https://doi.org/10.17977/jptpp.v3i12.12553. 
Wahyono, P., Husamah, H., \& Budi, A. S. (2020). Guru profesional di masa pandemi COVID-19: Review implementasi, tantangan, dan solusi pembelajaran daring. Jurnal Pendidikan Profesi Guru, 1(1), 51-65. https://doi.org/10.22219/jppg.v1i1.12462.

Wardani, Anita, \& Ayriza, Y. (2020). Analisis Kendala Orangtua dalam Mendampingi Anak Belajar di Rumah Pada Masa Pandemi Covid-19. Jurnal Pendidikan Anak Usia Dini, 5(1). https://doi.org/10.31004/obsesi.v5i1.705.

Wiastuti, Suadnyana, \& Kristiantari. (2014). Pengaruh Pembelajaran Siklus Belajar (Learning Cycle) Berbantuan Media Audio Visual Terhadap Hasil Belajar Ipa Siswa Kelas V Sd Gugus Budi Utomo. Mimbar PGSD Undiksha, 2(1). http://dx.doi.org/10.23887/jjpgsd.v2i1.2147.

Widiyono, A. (2020). Efektifitas Perkuliahan Daring (Online) pada Mahasiswa PGSD di Saat Pandemi Covid 19. Jurnal Pendidikan, 8(2), 169-177. https://doi.org/10.36232/pendidikan.v8i2.458.

Wulandari, H., \& Purwanta, E. (2021). Pencapaian Perkembangan Anak Usia Dini di Taman Kanak-kanak selama Pembelajaran Daring di Masa Pandemi Covid-19. Jurnal Obsesi : Jurnal Pendidikan Anak Usia Dini, 5(1). https://doi.org/10.31004/obsesi.v5i1.626.

Yulianingsih, W., Suhanadji, S., Nugroho, R., \& Mustakim, M. (2020). Keterlibatan Orangtua dalam Pendampingan Belajar Anak selama Masa Pandemi Covid-19. Jurnal Obsesi : Jurnal Pendidikan Anak Usia Dini, 5(2), 1138-1150. https://doi.org/10.31004/obsesi.v5i2.740. 